\title{
Perbandingan Sistem Kesehatan di Negara Berkembang dan Negara Maju
}

\author{
Ririn Noviyanti Putri \\ Mahasiswa Program Studi Magister IImu Kesehatan Masyarakat Universitas Sriwijaya \\ Email : ririnnoviyanti95@gmail.com
}

\begin{abstract}
The health system is a term that includes personal, institutions, financing, information, commodities and Government governance strategy in providing prevention and treatment services to the community. The health system was created with the aim of can respond to the needs and expectations of the community-owned healthcare in fulfillment of a fair and equitable. Then, good healthcare in developing countries as well as developed countries do need a reform, reorientation, and revitalization. This study aimed to know the comparison of health systems in developed and developing countries. Analysis study of the writing is done through literature review. Developing countries and developed countries experienced many challenges in building a strong health system and reliable. Health systems in developed countries look better compared to developing countries, it can be seen from the public health status and health problems. Health systems in each country vary greatly, but one has the same objective namely to enhance public health degrees extended. Every developed country or developing country has pros and cons of each of any health system that has been applied. The success of a health system of a country depends on the spirit, dedication, perseverance, hard work, good teamwork, ability (Human Resources, facilities), the sincerity of the organizers, as well as the participation of the community in order to achieve Universal Health Coverage in increasing degrees of better public health.
\end{abstract}

\section{Keywords:}

health systems; developing countries; developed countries; universal health coverage

\section{PENDAHULUAN}

Sistem kesehatan merupakan suatu istilah yang mencangkup personal, lembaga, komoditas, informasi, pembiayaan dan strategi tata pemerintah dalam memberikan layanan pencegahan dan pengobatan kepada masyarakat. Sistem kesehatan dibuat dengan tujuan dapat merespon kebutuhan dan harapan yang dimiliki masyarakat dalam pemenuhan pelayanan kesehatan yang adil dan merata. Hal ini tertuang dalam UUD 1945, yang menegaskan bahwa "setiap orang berhak hidup sehat serta berhak memperoleh pelayanan kesehatan", Pasal $28 \mathrm{H}$ angka (1) "negara bertanggung jawab atas penyediaan fasilitas pelayanan kesehatan bagi seluruh warga negaranya" (Sarwo YB, 2012).

Sistem kesehatan menurut Organisasi Kesehatan Dunia (WHO) merupakan "sebuah kegiatan yang bertujuan dalam mempromosikan, memulihkan, atau menjaga kesehatan". Sistem kesehatan yang baik sangat penting dalam mencapai Millennium Development Goals (MDGs). World Health Organization (WHO) telah mengidentifikasi 6 komponen yang harus diperlukan dalam menetapkan, mempertahankan dan memperkuat sistem kesehatan. Negara-negara berkembang telah banyak menghadapi tantangan dalam membangun sistem kesehatan yang kuat dan handal. Tantangan yang dihadapi antara lain pembiayaan pelayanan kesehatan yang tidak memadai, kurangnya koordinasi antar lembaga, serta kurangnya tenaga kesehatan (Gotama Indra, et all, 2010).
Indonesia adalah negara kepulauan terbesar di dunia, dengan jumlah penduduk lebih dari 240 juta jiwa Indonesia berada di peringkat keempat dunia. Terjadi pergeseran demografis pada populasi usia kerja yang meningkat relatif terhadap populasi lainnya. Indonesia juga termasuk status ekonomi yang berpenghasilan menengah ke bawah. Dari sistem pemerintahan dan politik Indonesia juga mengalami transisi di Tahun 1998 dari sistem demokrasi otoriter sekarang menjadi demokrasi reformasi. Perubahan tersebut juga mempengaruhi sistem kesehatan di Indonesia (Mahendradhata, Yodi, et all, 2017).

Prinsip pelayanan kesehatan masyarakat mengutamakan pelayanan promotif dan preventif. Pelayanan promotif adalah upaya meningkatkan kesehatan masyarakat agar lebih baik dan pelayanan preventif merupakan upaya dalam mencegah masyarakat agar terhindar dari suatu penyakit (Setyawan Budi, 2018). Krisis ekonomi di Indonesia berdampak pada pelayanan kesehatan. Maka dari itu pelayanan kesehatan melakukan sebuah reformasi, reorientasi, dan revitalisasi (Juanita, 2015). Reformasi kebijakan pembangunan kesehatan telah dilakukan. Reformasi Sistem Kesehatan Nasional (SKN) telah memberikan suatu perubahan dalam pembangunan kesehatan di Indonesia. Kebijakan dari SKN ini telah banyak melakukan perubahan, salah satunya dalam hal perubahan subsistem upaya kesehatan dan pembiayaan kesehetan (Gotama Indra, et all, 2010).

Salah satu indikator pelayanan kesehatan adalah lamanya waktu tunggu. Lama waktu 
tunggu ini dihitung dari saat mendaftar sampai mendapatkan pelayanan medis. Hasil SUSENAS 2016 memperlihatkan bahwa waktu tunggu diatas 30 - 60 menit diakui oleh $37,05 \%$ pasien rawat jalan, sedangkan pasien rawat inap lebih besar yaitu $45,43 \%$. Pengeluaran out of pocket juga didapat rata-rata untuk rawat jalan baik yaitu Rp.97.487,07. Sedangkan untuk rawat inap cukup besar yaitu mencapai $R p$ 2.735.803,72 (BPS, 2016).

Selain masalah penyakit menular dan akses pelayanan kesehatan, sistem jaminan kesehatan juga menjadi perhatian serius. Dengan mengusung sistem gotong royong BPJS (Badan Penyelenggara Jaminan Sosial) Kesehatan menyatakan total biaya jaminan kesehatan dari tahun 2014 s.d 2016 terus meningkat. Tahun 2014 dengan biaya total 42 Triliun rupiah untuk peserta 133,4 juta penduduk. Tahun 2016 mencakup pelayanan untuk 171,9 juta penduduk dengan biaya 69 triliun rupiah (Idris, Fachmi Prof, 2017).

Pembiayaan kesehatan yang kuat, stabil dan berkesinambungan sangat berpengaruh dalam penyelenggaraan pelayanan kesehatan guna mencapai tujuan penting pembangunan kesehatan di suatu negara yakni pemerataan dalam pelayanan kesehatan dan akses (equitable access to health care) serta pelayanan yang berkualitas (assured quality). Reformasi kebijakan sistem kesehatan di suatu negara sangat berdampak positif pada kebijakan pembiayaan kesehatan dalam menjamin terselenggaranya kecukupan (adequacy), pemerataan (equity), efisiensi (efficiency) dan efektifitas (effectiveness) dari pembiayaan kesehatan itu sendiri. (Setyawan Budi, 2018)

\section{METODE PENELITIAN}

Analisis kajian dari penulisan ini dilakukan melalui literatur review terkait dengan masalah sistem kesehatan yang ada di beberapa negara maju dan negara berkembang, baik dari sudut sistem kesehatannya itu sendiri yaitu lembaga, komoditas, informasi, pembiayaan dan strategi tata pemerintah dalam memberikan layanan pencegahan dan pengobatan kepada masyarakat. Literature review ini dilakukan dengan berbagai sudut pandang, teori, jurnal dan artikel untuk mempelajari dan mengetahui perbandingan dari sistem kesehatan yang dianut oleh beberapa negara maju maupun negara berkembang.

\section{HASIL DAN PEMBAHASAN \\ Sistem Kesehatan di Negara Berkembang Indonesia}

Indonesia merupakan salah satu negara berkembang yang telah menghadapi beberapa perubahan dan tantangan strategis yang mendasar. Tujuan bangsa Indonesia tertuang dalam pembukaan UUD 1945 yang diselenggarakan melalui pembangunan nasional termasuk pembangunan kesehatan. Dalam mendukung terlaksananya pembangunan kesehatan memerlukan dukungan dari Sistem Kesehatan Nasional yang kuat. SKN dijadikan sebuah acuan dalam pendekatan pelayanan kesehatan primer. Hal ini merupakan sebuah pendekatan yang tepat untuk mencapai derajat kesehatan masyarakat yang diformulasikan sebagai visi Indonesia Sehat (Adisasmito Wiku, 2009).

Sistem Kesehatan Nasional (SKN) merupakan pengelolaan kesehatan yang diselenggarakan oleh semua komponen Bangsa Indonesia secara terpadu dan saling mendukung guna menjamin tercapainya derajat kesehatan masyarakat yang setinggi-tingginya. Untuk mencapai tujuan pembangunan kesehatan, maka pengelolaan kesehatan dilaksanakan melalui subsistem kesehatan yang terbagi ke dalam beberapa bagian, yaitu upaya kesehatan, penelitian dan pengembangan kesehatan, pembiayaan kesehatan, sumber daya manusia kesehatan, sediaan farmasi, alat kesehatan, dan makanan, manajemen, informasi dan regulasi kesehatan, pemberdayaan masyarakat (Peraturan Presiden Republik Indonesia, 2012).

Sistem kesehatan suatu negara sangat dipengaruhi oleh kebijakan-kebijakan kesehatan yang ditetapkan oleh penentu kebijakan baik pemerintah atau swasta. Kebijakan kesehatan itu sendiri dipengaruhi oleh segitiga kebijakan yakni konteks (faktor ekonomi, sosial budaya, politik), konten/isi, proses pengambilan kebijakan dan aktor yang berperan (policy elites) (Buse, Kent, et all, 2005). SKN Indonesia memiliki 3 landasan meliputi landasan idiil yaitu Pancasila, landasan konstitusional yaitu UUD Negara RI khususnya pasal 28 dan 34, dan landasan operasional yaitu UU Nomor 36 Tahun 2009 tentang Kesehatan (Peraturan Presiden Republik Indonesia, 2012).

World Health Report 2000 yang berjudul Health System : Improving Performance menetapkan tujuan normative sistem pelayanan kesehatan, yakni (Siswanto, 2010):

a. Peningkatan status kesehatan (goodness of health)

b. Peningkatan mutu pelayanan kesehatan (responsiveness)

c. Peningkatan keadilan dalam pembiayaan kesehatan (fairness of health financing)

Universal Coverage (cakupan semesta) merupakan suatu sistem kesehatan yang bertujuan untuk masyarakat dalam mendapatkan akses pelayanan kesehatan yang bermutu sesuai dengan kebutuhan masyarakat serta dengan biaya yang terjakau oleh masyarakat, antara lain pelayanan kesehatan promotif, preventif, kuratif dan rehabilitative (Siswanto, 
2010). Cakupan semesta terbagi atas dua elemen yakni akses pelayanan kesehatan yang adil dan bermutu dan perlindungan risiko finansial (WHO, 2005). Sedangkan cakupan semesta terkait sistem pembiayaan terbagi atas 3 kategori, yakni pembayaran tunggal (single payer), pembayaran ganda (two-tier, dual health care system), dan sistem mandat asuransi (Murti Bhisma, 2011).

Salah satu dampak positif dari jaminan kesehatan semesta berupa peningkatan utilisasi pelayanan, namun diduga mengakibatkan moral hazard dan penurunan motivasi di sisi para penyedia layanan. Masalah utama yang ditemui biasanya adalah sustainability dari sistem berobat gratis karena kurang diperhitungkannya kebutuhan anggaran dan lemahnya mekanisme pengendalian biaya. Kebijakan berobat gratis bahkan dianggap hanya suatu kebijakan yang bersifat politis untuk memenuhi 'janji pemilu' yang justru merugikan sistem kesehatan (Dewi, Shita, 2013).

Tujuan perencanaan dan pengaturan pembiayaan kesehatan yang memadai dapat membantu memobisasikan sumber pembiayan kesahatan, mengalokasi dengan rasional serta dapat digunakan secara efektif dan efisien. Pembiayaan kesehatan mempunyai kebijakan dengan mengutamakan pemerataan serta berfokus pada masyarakat yang tidak mampu (equitable and pro poor health policy) yang dapat membantu mencapai akses kesehatan yang universal (Setyawan Budi, 2018). Sistem kesehatan di Indonesia didukung dengan pembiayaan pemerintah yang bersumber dari pemerintah pusat maun pemerintah daerah. Anggaran dari pemerintah pusat disalurkan melalui DAU, DAK, DAK non fisik, serta Jaminan Kesehatan Nasional (JKN). Sedangkan anggaran dari pemerintahan daerah dalam bentuk dukungan program pusat maupun untuk pembiayaan program inovasi daerah sendiri. Pengelola sistem pembiayaan di Indonesia yakni kementerian kesehatan sebagai regulator, monitor dan mengevaluasi pelaksanaan sistem kesehatan. Sedangkan badan pengumpul dan penyalur premi melalui kapitasi dan INA CBG'S adalah BPJS (Dewi Shita, 2017).

Permasalah yang timbul dari pembiayaan kesehatan antara lain kurangnya dana serta adanya peningkatan dana. Kurangnya dana terjadi karena terdapatnya inefisiensi dalam pengelolaan pembiayaan dan alokasi dana yang salah. Sedangkan yang dimaksud peningkatan biaya yaitu adanya trend peningkatan teknologi kedokteran sebagai penegak diagnosis (evidence bases) yang menyebabkan konsekuensi biaya, serta tren suppy induce demand yang banyak marak sekarang ini (Trisnantoro L, 2014). Selain itu, dominasi pembiayaan dengan mekanisme fee for service, dan masih kurangnya dalam mengalokasikan sumber-sumber dan pelayanan itu sendiri (poor management of sesources and services) (Depkes, 2009).

Sistem Kesehatan di Indonesia untuk sekarang sudah menuju ke arah yang lebih baik, meskipun masih banyak terdapat banyak macam kendala. Hal ini dapat dilihat dari terdapatnya peningkatan status kesehatan masyarakat. Akan tetapi, meskipun terjadi peningkatan status kesehatan masyarakat, namun masih diperlukan upaya percepatan pencapaian indikator kesehatan dalam rangka mengejar ketertinggalan dari negara lain, sehingga SKN masih perlu terus dilakukan evaluasi dan perbaikan.

Akses pelayanan kesehatan yang adil menggunakan prinsip keadilan vertikal. Prinsip keadilan vertikal menegaskan, kontribusi warga dalam pembiayaan kesehatan ditentukan berdasarkan kemampuan membayar (ability to pay), bukan berdasarkan kondisi kesehatan/ kesakitan seorang. Dengan keadilan vertikal, orang berpendapatan lebih rendah membayar biaya yang lebih rendah daripada orang berpendapatan lebih tinggi untuk pelayanan kesehatan dengan kualitas yang sama. Dengan kata lain, biaya tidak boleh menjadi hambatan untuk mendapatkan pelayanan kesehatan yang dibutuhkan (needed care, necessary care) (Murti Bhisma, 2011).

\section{Malaysia}

Malaysia negara berpenduduk terbanyak ke 43 dan negara dengan daratan terluas ke-66 di dunia dengan jumlah penduduk kira-kira 27 juta dan luas wilayah melebihi $320.000 \mathrm{~km}^{2}$. Berbeda dengan Indonesia yang melaksanakan jaminan kesehatan semesta pada tahun 2014 dan baru akan merampungkan total populasi pada tahun 2019, negara tetangga Malaysia justru sudah melaksanakannya sejak tahun 1990an (Idris Haerawati, 2017). Namun adanya beberapa isu krusial melibatkan kenaikan biaya, keberlanjutan jangka panjang, kenaikan pajak, efisiensi dan harapan masyarakat akan kualitas pelayanan yang lebih tinggi, Malaysia merubah sistem kesehatannya dari layanan kesehatan yang sebelumnya didominasi pemerintah, saat ini justru lebih besar melibatkan sektor swasta (Chongsuvivatwong, Virasakdi, et all, 2011).

$$
\text { Malaysia juga mengembangkan }
$$

kesehatan sebagai daya tarik wisatawan berkunjung ke negaranya. Jarak yang tidak jauh dari Indonesia yang memiliki 240 juta penduduk, membuat Malaysia meningkatkan kualitas rumah sakitnya. Salah satu penghargaan Malaysia adalah memenangkan Medical Travel Destination of The Year 2015 di International Medical Travel Journal (IMTJ). Tidak heran jika Malaysia terutama Kuala Lumpur dan Penang 
jadi negara tujuan utama untuk berlibur sekaligus menjaga kesehatan (medical check up) (Futuready, 2016).

$$
\text { Malaysia }
$$

sistem

pembiayaan

kesehatannya lebih maju dibandingkan dengan Indonesia, karena Malaysia merupakan negara persemakmuran Inggris. Pada tahun 1951 malaysia mewajibkan tabungan wajib bagi pegawai yang nantinya dapat digunakan sebagai tabungan dihari tua. Sedangkan warga yang tidak diwajibkan akan difasilitasi oleh sebuah lembaga yakni EPF (Employee Provident Fund). Lembaga SOSCO (Social Security Organization) menjamin warga yang mendapat kecelakaan kerja atau pensiunan cacat (Purwoko Bambang, 2014).

Sistem pembiayaan kesehatan yang ada di Malaysia terdiri dari kesehatan publik dan kesehatan privat. Sumber dana untuk kesehatan publik berasal dari pajak masyarakat kepada pemerintah federal, anggaran pendapatan negara, serta lembaga SOSCO dan EPF, yang mana dana yang ada tersebut disalurkan untuk program keehatan preventif dan promotif.pemerintah Malaysia menetapkan Universal Coverage untuk program kesehatan kuratif dan rehabilitative, yang mana semua masyarakat dijamin pelayanan kesehatannya denganmembayar iuran sebesar 1 RM untuk mendapatkan pelayanan kesehatan dari dokter umum, sedangkan untuk pelayanan dari dokter spesialis sebesar 5 RM. Akan tetapi sistem pembiayaan kesehatan di Malaysia ini tidak termasuk dalam kategori penyakit berat yang membutuhkan biaya pengobatan yang tinggi (Jaafar, Safurah Noh, et all, 2013).

Pemerintah malaysia membebaskan pajak untuk alat kesehatan dan obat-obatan, yang berdampak pada biaya operasional di Malaysia yang menjadi murah. Pemerintah Malaysia membatasi praktik dokter yang hanya satu tempat, sehingga dokter harus memilih akan praktik di pelayanan kesehatan milik pemerintah atau milik swasta. Selain itu, dengan adanya feed back atau pemasukan dari dokter yang tinggi, tentu akan mempengaruhi kualitas pelayanan. Untuk mengklaim pembiayaan kesehatan, rumah sakit pemerintah melihat besarnya pengeluaran yang terjadi di tahun sebelumnya dan kemudian rumah sakit tersebut baru bias untuk mengajukan anggaran kepada Kementerian Kesehatan / Ministry of Health $(\mathrm{MoH})(\mathrm{WHO}, 2005)$.

\section{Thailand}

Thailand memulai sistem jaminan kesehatan di negaranya sejak tahun 1990an yang saat itu baru mencakup $16 \%$ dari populasi (pegawai negeri dan pekerja formal), pada tahun 2002, sudah mencakup seluruh penduduk (National Health Security) yang diperkirakan sudah mencakup $75 \%$ dari seluruh penduduk. ${ }^{23}$ Semenjak tahun 2002 tersebut Thailand telah mencapai Universal Health Coverage sebagai sistem kesehatan di negaranya. Sedangkan pada tahun 2009, penduduk Indonesia sebanyak $30,1 \%$ untuk mendapatkan pelayanan kesehatan masih mengeluarkan uang secara out of pocket. Thailand dalam mencapai sistem kesehatan universal health coverage, hampir setegah decade mengalami evolusi sejarah yang cukup panjang, evolusi tersebut dimulai dari sitem pembiayaan secara out of pocket sampai bertahap mencapai sistem pembiayaan di muka. Thailand telah menguji dan memperkenalkan berbagai sistem pembiayaan untuk mendapatkan pelayanan kesehatan. (Indrayathi PA, 2016)

Thailand dalam mencapai sistem kesehatan UHC, masyarakatnya sebanyak 99\% dilindungi dengan 3 skema, yaitu Universal Health Coverage (cakupan semesta 75\%), Social Health Insurance for formal private sector (skema asuransi kesehatan untuk pegawai swasta 20\%), dan Civil Servant Medical Benefit Scheme (skema asuransi kesehatan untuk PNS $5 \%$ ). Strategi pembiayaan yang baik sangat dibutuhkan untuk mendukung skema tersebut. Thailand membuat salah satu strategi, yakni menghilangkan kendala keuangan, yang mana strategi tersebut mempunyai resiko yang besar untuk memperluas skema UHC bagi masyarakat yang belum memiliki asuransi kesehatan, agar dapat dengan sukarela menggabungkan kartu asuransi dengan kartu identitas lain (LIC) (Indrayathi PA, 2016).

Sistem pelayanan rujukan merupakan sistem pelayanan kesehatan yang diterapkan oleh Thailand. Sistem tersebut dimulai dari primary care unit sebanyak $\leq 8000 \mathrm{PCU}$, rumah sakit distrik atau biasa disebut rumah sakit sekunder dan tersier sebanyak 800 unit di level provinsi maupun rumah sakit pendidikan. Sedangkan rumah sakit promotif dan preventif yakni merupakan PCU yang mana PCU ini harus mempunyai standard layanan minimum yang harus ditetapkan secara nasional. Pengembangan infrastruktur dibutuhkan dalam implementasi sistem UHC. Selain itu dalam pengimplementasian ini juga dibutuhkan SDM yang berkualitas serta bersedia bekerja sepenuh hati, yang mana SDM tersebut memerlukan motivasi dan passion dalam memberikan pelayanan semaksimal mungkin pada masyarakat. Thailand mempunyai health center, yang mana SDM berkualitas tersebut diletakkan di perdesaan. SDM tersebut merupakan tenaga kesehtan maupun non kesehatan yang akan dilatih dalam memberikan pelayanan yang baik bagi masyarakat (Indrayathi PA, 2016).

Pemerintah Thailand juga memberikan kesempatan bagi kader-kader tenaga kesehatan 
untuk membuka lowongan tenaga kesehatan yang akan mengabdi di perdesaan. Selain itu, pemerintah juga memberikan putra daerah kesempatan untuk menyekolahkan mereka di fakultas kesehatan yang mana kedepannya putra daerah tersebut akan ditempatkan di daerah asalnya sebagai tenaga kesehatan dan akan diberikan dukungan seperti insentif yang memadai. pemerintah Thailand juga mempersiapkan kader-kader tenaga kesehatan dengan membuka lowongan tenaga kesehatan untuk bekerja di pedesaan dan menyekolahkan putra daerah di fakultas-fakultas kesehatan. Nantinya, putra daerah ini diminta untuk mengabdi sebagai tenaga kesehatan di daerah asalnya dan pemerintah menyediakan insentif yang memadai sebagai bentuk dukungan (Indrayathi PA, 2016).

Jumlah dokter di Thailand sudah sangat banyak dibandingkan dengan Indonesia. Sementara persentase tenaga kesehatan (bidan, perawat) Indonesia jauh lebih banyak dari Thailand. Terdapat 20 bidan di Indonesia per 100.000 penduduk, sementara di Thailand hanya 1 bidan per 100.000 penduduknya. Dapat diasumsikan bahwa Indonesia masih memprioritaskan pelayanan di tingkat pertama untuk menjangkau masyarakat di daerahdaerah, sedangkan Thailand sudah tidak mempunyai masalah akses layanan tingkat pertama, sehingga lebih memprioritaskan di layanan tingkat lanjut (penyediaan layanan rumah sakit dan dokter). (Indrayathi PA, 2016)

Keberhasilan Thailand dengan mutu pelayanan rumah sakitnya dapat dilihat juga dari salah satu Rumah Sakit Internasional di Bangkok "Bumrungrad International Hospital" menjadi salah satu tujuan wisata kesehatan. Mengusung tema serupa dengan hotel bintang 5, RS ini mendesain interiornya bernuansa modern tanpa ada aroma obat yang menyengat. Perawat dan para dokter dilatih dengan prosedur internasional, dengan perawatan yang menggunakan peralatan sangat canggih. Terutama pusat-pusat medis dengan spesialisasi sebagai berikut, kardiologi (jantung), onkologi (kanker), neurologi (sistem saraf) / neonatal (bayi), Gl (penyakit pencernaan), ortopedi (tulang, otot, ligamen), hingga optometry (mata). (Futuready, 2016)

\section{Sistem Kesehatan di Negara Maju Jepang}

Salah satu negara dengan harapan hidup tertinggi yakni Jepang (WHO, 2011). Selain itu, jepang juga merupakan negara kedua yang mempunyai tingkat harapan hidup tinggi perkelahiran dengan rata-rata umur adalah 82,8 tahun berdasarkan penelitian yang dilakukan oleh OECD pada tahun 2013. (Broida, Joel H \& Maeda, et all, 2014) Berdasarkan data tersebut, dapat kita simpulkan bahwa Jepang merupakan negara yang pastinya negara yang memiliki teknologi kesehatan yang canggih dan lengkap sesuai dengan kebutuhan masyarakat. akan tetapi, Jepang mengalami kendala akibat dari teknologi yang canggih itu, karena memicu pengeluran pembiayaan yang meningkat. (Widodo Teguh, 2014)

Dari segi pembiayaan kesehatan, pemerintah Jepang sudah memulai jaminan kesehatan sejak tahun 1927, dan mencakup seluruh penduduk (whole coverage) di tahun 1961. Untuk penduduk lansia bahkan digratiskan atau tidak perlu membayar iuran sejak tahun 1973. (Ikegami, Naoki, et all, 2004) Negara Jepang menyediakan pelayanan kesehatan kepada masyarakat mencangkup seluruh populasi melalui sistem asuransi kesehatan. Para pekerja pada sektor swasta yang pertama kali dikenalkan pada asuransi kesehatan public di Jepang yang berlandaskan hukum The Health Insurance Law pada tahun 1992. (Fukawa, Tetsuo, 2002) Akan tetapi asuransi kesehatan yang mencangkup para pekerja tersebut memiliki manfaat yang tidak komprehensif. Setelah pasca perang kedua di Jepang, Jepang berupaya dalam meningkatkan sistem kesehatan yang ada, termasuk asuransi kesehatan bagi masyarakat Jepang. Subsidi pemerintah pada tahun 1954 ditetapkan sepihak oleh pemerintah nasional untuk kepentingan asuransi kesehatan satu milyar yen. Hal ini untuk memenuhi cakupan dalam universal asuransi kesehatan publik yang akan tercapai pada tahun 1961. (Ikegami, Naoki, et all, 2004)

Sistem asuransi di Jepang tidak semua pengobatan maupun perawatan akan ditanggung oleh asuransi, tetapi akan ditanggung secara bersama oleh pihak asuransi dan juga pasien yang bersangkutan. Pemerintah Jepang pada tahun 1984 mengeluarkan sebuah kebijakan, yang mana kebijakan tersebut berisi bahwa masyarakat wajib membayar seluruh pengobatan sebesar $10 \%$, sedangkan pada tahun 1997 terjadi peningkatan sebesar 20\%, dan tahun 2003 hingga kini terus terjadi peningkatan hingga $30 \%$. Akan tetapi peningkatan sebesar $30 \%$ tersebut tidak berlaku untuk semua masyarakat. sharing cost asuransi kesehatan di Jepang yang berlaku saat ini, yaitu : (Fukawa, Tetsuo, 2002)

a. Umur $\geq 75$ tahun membayar $10 \%$, bila mempunyai pendapaatan sebesar income maka naik menjadi 30\%.

b. Umur 70-75 tahun membayar 20\%, bila mempunyai pendepataan sebesar income maka naik menjadi 30\%.

c. Mulai wajib belajar - umur 70 tahun membayar sebesar $30 \%$.

d. Anak yang belum sekolah membayar $30 \%$. 
Sumber daya di Jepang mempunyai kualitas yang cukup baik yang dapat membantu negara Jepang dalam mewujudkan sistem jaminan kesehatan yang baik dan berkualitas bagi masyarakat. jaminan kesehatan akan diberikan sesuai dengan program yang diikuti oleh peserta, yang terdiri dari penyakit umum sampai dengan penyakit khusus. Jepang memiliki pelayanan kesehatan berupa rumah sakit sebanyak $\geq 1000$ rumah sakit mental, general hospital 8700 unit, comprehensive hospital 1000 unit dengan kapasitas BOR 1,5 juta, 48.000 klinik gigi, dan 79.000 pelayanan kesehatan yang dilengkapi fasilitas layanan rawat jalan dan rawat inap. (Fukawa, Tetsuo, 2002)

Berbagai macam asuransi yang ada di Jepang, yaitu : (Ikegami, Naoki, et all, 2004)

a. National Health Insurance, dikelola oleh pemerintah, yang mana asuransi ini ditujukan untuk masyarakat yang sudah pension, orang usia lanjut $<75$ tahun, masyarakat yang tidak mampu, serta masyarakat yang menganggur.

b. Japan Health Insurance, dikelola oleh pemerintah yang ditujukan untuk karyawan yang bekerja disebuah perusahaan yang kecil $<7000$ orang karyawan.

c. Association/Union Administered Health Insurance, dikelola oleh swasta yang ditujukan untuk karyawan yang bekerja diperusahaan besar $>7000$ orang karyawan.

d. Mutual Aid Insurance, dikelola oleh pemerintah yang ditujukan untuk pegawai negeri.

e. Advanced Eldery Medical Service System, dikelola oleh pemerintah yang ditujukan untuk masyarakat lansia $>75$ tahun.

Di Jepang, dalam mendapatkan pelayanan kesehatan di rumah sakit maupun pelayanan dokter diberlakukan secara sama untuk semua sistem asuransi yang dipakai. Pembayaran yang dipakai berupa fee for service, tetapi secara parsial telah digunakan sebagai pembayaran paket pada asuransi Health Insurance for Elderly. Masing-masing harga perawatan medis telah terdaftar oleh asuransi pada fee schedule berdasarkan rekomendasi The Central Social Insurance Medical Council yang ditentukan oleh pemerintah. Harga resep obat yang dapat diklaim oleh fasilitas medis berdasarkan standard harga obat-obatan.

Ada persamaan jaminan kesehatan di Jepang dengan Indonesia yaitu beban biaya perawatan penduduk lanjut usia cenderung tinggi. Hal tersebut terkait pola penyakit degeneratif dan jumlah proporsi penduduk lansia di Jepang yang tinggi. Namun yang berbeda adalah jaminan kesehatan di Jepang tidak mengenal sistem rujukan, penduduk bebas memilih layanan kesehatan di dokter atau klinik tingkat pertama, ataupun langsung ke RS. Namun jaminan kesehatan di Jepang tidak mencakup persalinan normal, sedangkan di Indonesia mencakup semua persalinan baik normal maupun operasi (SC) dengan indikasi medis. (Pernando, Anggara, 2015)

\section{Australia}

Australia merupakan salah satu negara maju yang memiliki perekenomian yang sangat bagus dan mempunyai berbagai sumber daya yang berkualitas. Australia memiliki sistem kesehatan yang canggih dan kompleks. Sistem kesehatan yang canggih tersebut didukung dengan kerjasama antara pelayanan kesehatan pemerintah maupun swastas. Akses pelayanan kesehatan yang dikelola oleh pemerintah Australia yakni bebas biaya. Meskipun terdapat akses pelayanan yang bebas biaya yang dapat ditanggung oleh pemerintah, beberapa masyarakat Australia juga menggunakan asuransi kesehatan dari pihak swasta. (Healy, Judith, and Paul Dugdale, 2013)

Rumah sakit swasta yang ada di Australia, salah satunya rumah sakit yang dikelola oleh Healthscope menyediakan berbagai pelayanan perawatan kesehatan, yakni pelayanan sub akut hingga pelayanan perawatan kesehatan yang kompleks. Kualitas perawatan di Australia sangat terkenal diseluruh dunia karena memiliki pelayanan yang sangat baik. Berdasarkan penelitian internasional di lima negara yang menilai sistem kesehatan di Australia, Kanada, Jerman, New Zeland, dan Amerika Serikat), Australia mendapatkan penilaian sistem kesehatan yang sangat baik dan menduduki peringkat kedua dari lima negara tersebut. Selain itu, Australia juga mendapatkan penilaian yang sangat baik dari hasil penilaian pelayanan kesehatan yang diukur oleh OECD. (Healy, Judith, and Paul Dugdale, 2013)

Sistem kesehatan di Australia telah mencapai Universal Health Coverage. Untuk mencapai sistem kesehatan tersebut, banyak yang dilakukan oleh pemerintah Australia yang dikembangkan secara terus-menerus selama puluhan tahun yang lalu. Australia memiliki sistem perawatan kesehatan yang didanai oleh pemerintah, dengan layanan medis yang disubsidi melalui skema asuransi kesehatan nasional universal. Sebagai perbandingan anggaran kesehatan Australia USD3.484 per kapita, sedangkan Indonesia masih sekitar USD100 per kapita. (Healy, Judith, and Paul Dugdale, 2013)

Berbeda dengan Indonesia, sistem pembiayaan kesehatan di Australia berasal dari pajak, sehingga pelayanan untuk masyarakat sama tidak ada perbedaan kelas premi. Kesehatan masyarakat juga menjadi perhatian pemerintah Australia. Angka penyakit menular 
dapat ditekan, sanitasi dan kualitas air juga menjadi fokus pemerintah. Pemerintah juga mengembangkan penelitian-penelitian kesehatan berbasis epidemiologi. Berbagai hal tersebut dilakukan untuk meningkatkan status kesehatan masyarakatnya. Status kesehatan masyarakat di Australia sudah sangat baik, misalnya untuk cakupan imunisasi lengkap di Indonesia baru sekitar 59,2\% (RISKESDAS, 2013) sedangkan di Australia cakupan imunisasi lengkap sudah mencapai 90\%. (Healy, Judith, and Paul Dugdale, 2013)

Salah satu studi yang dilakukan oleh Commonwealth Fund terhadap 11 model perawatan kesehatan nasional yang berbeda, menemukan sistem jaminan kesehatan campuran publik dan privat milik Australia menduduki peringkat terbaik kedua dunia. Hal tersebut diakui oleh Presiden Amerika Serikat yang mengatakan sistem kesehatan negaranya "Obamacare" perlu segera diperbaiki. Dan menyatakan negara-negara lain perlu belajar sistem kesehatan Australia. (Healy, Judith, and Paul Dugdale, 2013)

\section{Amerika Serikat}

Sistem kesehatan di Amerika menerapkan sistem asuransi komersial. Asuransi komersial tersebut artinya masyrakat berhak memilih untuk menggunakan asuransi atau tidak. Hal ini menyebabkan biaya operasional menjadi besar, premi meningkat setiap tahun, mutu pelayanan kesehatan diragukan, dan tingginya unnecessary utilization karena AS memiliki sitem pembiayaan fee for services. biaya kesehatan menjadi beban yang sangat berat bagi pemerintah AS karena biaya kesehatan melambung tinggi dan mancapai 12\% GNP. Tingginya biaya kesehatan menyebabkan tingginya pula biaya produksi barang dan jasa. Pemerintah AS membuat kebijakan berbentuk undang-undang pada tahun 1973 untuk meminimalisir pertumbahan conventional health insurance yakni kebijakan Health Maintenance Organization (HMO-ACT). (Trisnantoro L, 2014)

Sistem kesehatan yang diterapkan di AS merupakan sistem yang berorientasi pasar, yang mana sepertiga pembiayaan kesehatan ditanggung oleh pasien (out of pocket). Biaya kesehatan di AS sangat tinggi berdampak pada kondisi Produk Domestik Bruto (PDB). Biaya kesehatan yang dikeluarkan oleh masyarakat AS sebesar $16 \%$ dari total PDB. Biaya yang dikeluarkan masyarakan sangat tinggi dan merupakan peringkat kedua di dunia dalam penggunaan PDB untuk kesehatan. Jika masalah ini tidak diatasi dan diselesaikan dengan baik, maka menurut The Health and Human Service Departement anggka penggunaan PDB akan mengalami peningkatan yang dratis pada tahun 2017 hingga mencapai
19,5\%. Layanan kesehatan di AS juga termasuk kategori mahal diseluruh dunia, bagi standard Negara maju indicator kesehatan yang ada di AS tergolong buruk. (Trisnantoro L, 2014)

Pelayanan kesehatan di Amerika Serikat sebagian dikelola oleh pihak swasta. Pada tahun 2009, tercatat sebanyak 50,7 juta penduduk Amerika Serikat yang tidak memiliki asuransi kesehatan (The US Censuss Beureau). Penduduk yang tidak tersentuh asuransi tersebut salah satunya berasal dari masyarakat kalangan berpenghasilan menengah kebawah. Hal ini menyebabkan perusahaan banyak mengalami bangkrut dikarenakan mahalnya pembiayaan kesehatan. Peristiwa ini membuat masyarakat AS bergejolak untuk menuntut untuk dilakukannya reformasi dalam hal kesehatan. Pemerintah AS dituntut untuk memegang kendali dalam permasalahan asuransi kesehatan ini. Masyarakat AS sangat membutuhkan perawatan, akses, keadilan, efisiensi, biaya, pilihan, nilai dan kualitas yang memadai. Pemerintah AS akhirnya membuat sebuah terobosan baru mengenai sebuah kebijakan dalam bidang kesehatan. Patient Protection Avordable Care Act (PPACC) merupakan salah satu kebijakan yang telah dibuat oleh pemerintah AS. Titik tolak dari perkembangan kesehatan di AS berdasarakan dari kebijakan tersebut. Selain itu, kebijakan tersebut menjadi landasan hukum AS dalam menyelenggarakan perawatan dan biaya kesehatan yang efektif dan efisien bagi masyarakat AS. Dengan dilakukannya reformasi penerapan undang-undang ini diharapkan dapat menurunkan biaya asuransi kesehatan yang akan ditanggung masyarakat AS dimasa yang akan datang. (Trisnantoro L, 2014)

\section{SIMPULAN}

Sistem kesehatan di setiap negara sangat bervariasi, tapi memiliki satu tujuan yang sama yakni untuk meningkatkan derajat kesehatan masyarakat yang setinggi-tingginya. Setiap negara maju maupun negara berkembang mempunyai kelebihan dan kelemahan masing-masing dari setiap sistem kesehatan yang diterapkan. Sistem kesehatan yang lampau hingga kini disetiap negara mengalami perubahan yang lebih baik. Setiap pemerintahan negara berkembang maupun negara maju berusaha untuk bisa mengcover asuransi kesehatan bagi masyarakatnya. Sistem pembiayaan kesehatan ditiap negara juga berbeda, hal ini dikarenakan disetiap negara mempunyai perbedaan karakteristik penduduk, pemasukan negara, ekonomi, dan geografis yang sangat berpengaruh.

Negara berkembang dan negara maju banyak mengalami berbagai tantanggan dalam membangun sistem kesehatan yang kuat dan handal. Sistem kesehatan di negara maju terlihat lebih baik dibandingkan dengan negara berkembang, hal ini dapat di lihat dari status kesehatan masyarakat dan permasalahan kesehatan. Sistem Kesehatan Nasional (SKN) di Indonesia sudah mampu memberikan 
peningkatan status kesehatan masyarakat Indonesia dari tahun ke tahun. Namun masih diperlukan upaya percepatan pencapaian indikator kesehatan dalam rangka mengejar ketertinggalan dari negara lain. Salah satu permasalahan di Indonesia seperti masih kurangnya tenaga kesehatan, akses pelayanan kesehatan yang kurang merata, pembiayaan kesehatan yang tidak tercover dengan baik, fasilitas yang kurang lengkap menjadi permasalahan dalam sistem kesehatan di Indonesia. Untuk itu kita perlu mempelajari atau mengadopsi sistem kesehatan di negara-negara yang sudah maju maupun negara berkembang lainnya, sehingga SKN di Indonesia dapat menjadi upaya kesehatan yang optimal dalam mewujudkan derajat kesehatan setinggi-tingginya.

\section{DAFTAR PUSTAKA}

Adisasmito Wiku. Sistem Kesehatan Edisi Kedua. Raja Grafindo Persada. 2009.

Badan Pusat Statistik. Statistik Kesehatan 2016 (Hasil Survei Sosial Ekonomi Nasional Modul Kesehatan Dan Perumahan 2016). BPS Jakarta. 2016

Broida, Joel H \& Maeda, et all. Japan's High Cost IIIness Insurance Program: A Study of its First Three Years. Public Health Reports. Association of Schools of Public Health. International Health. Vol 93 No 2. 2014.

Buse, Kent, et all. Making Health PolicyUnderstanding Public Health. 2005.

Chongsuvivatwong, Virasakdi, et all. Health in Southeast Asia 1: Health and healthcare systems in southeast Asia: diversity and transitions. Vol 377. 2011.

Departemen Kesehatan RI. Sistem Kesehatan Nasional. Jakarta. 2009.

Dewi, Shita. Sistem Pembiayaan dan Kebijakan Pengendalian Biaya. Jurnal Kebijakan Kesehatan Indonesia UGM, Vol. 02, No. 2. 2013.

Dewi Shita. Pemanfaatan Pembiayaan dalam Sistem Kesehatan di Indonesia. Jurnal Kebijakan Kesehatan Indonesia. Vol 06 No 03. 2017.

Fukawa, Tetsuo. Public Health Insurance in Japan. Washington : World Bank Institude. 2002.

Futuready Article. 5 Negara Tujuan Wisata Kesehatan di Asia. 2016.

Gotama Indra, Perdede Donald. Reformasi Jaminan Sosial Kesehatan (Pembiayaan Kesehatan dan Isu-Isu Jaminan Kesehatan). Pusat Pembiayaan dan Jaminan Kesehatan Depkes RI. Jakarta. 2010.

Healy, Judith, and Paul Dugdale.The Australian Health Care System. The Australian Univercity. 2013.

Idris, Fachmi Prof. Strengthening Indonesia's Health System through the National Health Security. Sriwijaya University International Conference on Public Health (SICPH):Public Health Responses to Health Systems Strengthening. Palembang. 2017.

Idris Haerawati. Global Issue Universal Health Coverage: Expanding health insurance among informal worker in Indonesia. Sriwijaya International Conference on Public Health (SICPH). Palembang. 2017.
Ikegami, Naoki, et all. Japan's Health Care System: Containing Costs And Attempting Reform. Health Affairs. 2004.

Indrayathi PA. Bahan Ajar Pembiayaan Kesehatan di Berbagai Negara. Program Studi Kesehatan Masyarakat Udayana. Denpasar. 2016.

Juanita. Peran Asuransi Kesehatan dalam Benchmarking Rumah Sakit dalam Menghadapi Krisis Ekonomi. Fakultas Kesehatan Masyarakat Jurusan Administrasi dan Kebijakan Kesehatan. Universitas Sumatera Utara. 2012.

Jaafar, Safurah Noh, et all. Malaysia Health System Review. Health System in Transation Vol 3 No1. 2013.

Mahendradhata, Yodi, et all. The Republic of Indonesia Health System Review. Health Systems in Transition Vol.7 No. 1. World Health Organization. 2017.

Murti Bhisma. Asuransi Kesehatan Berpola Jaminan Pemeliharaan Kesehatan Masyarakat di Era Desentralisasi Menuju Cakupan Semesta. Institute of Health Economic and Policy Studies (IHEPS). Universitas Sebelas Maret. 2011.

Peraturan Presiden Republik Indonesia Nomor 72. Sistem Kesehatan Nasional. Kementerian Kesehatan RI. 2012.

Purwoko Bambang. Sistem Jaminan Sosial di Malaysia: Suatu Tata Kelola Penyelenggaraan Program yang Berbasis pada Pelembagaan yang Terpisah. E-Journal Widya Ekonomika. ISSN 2338-7807. Vol 1 No 1. 2014.

Pannarunothai, Supasit. Using Utilisation Data to Estimate Future Demand of Health Care in Thailand Under The National Health Security. The Sriwijaya International Conference of Public Health (SICPH) Palembang, Indonesia. 2017.

Pernando, Anggara. Ini Beda Jaminan Kesehatan Nasional Rl dan Jepang. Ampshare Article. 2015.

Sarwo YB. Asuransi Kesehatan Sosial Sebagai Model Pembiayaan Kesehatan Menuju Jaminan Semesta (Universal Coverage). Fakultas Hukum Unika Soegijapranata. MMH Jilid 41 No 3. 2012.

Setyawan Budi. Health Financing System. Fakultas Kedokteran Universitas Muhammadiyah Malang. Vol 2 No 4. 2018.

Siswanto. Trade-off Analysis in Indonesian Health Services System Report. Badan Penelitian dan Pengembangan Kesehatan Kemkes RI. Jurnal Manajemen Pelayanan Kesehatan. Vol 13 No 2. 2010.

Trisnantoro L. Trend Pembiayaan Kesehatan di Berbagai Negara. Modul Magister Manajemen RS UGM. Yogyakarta. 2014.

WHO. Achieving universal health coverage: Developing the health financing system. Technical brief for policy-makers. World Health Organization, Department of Health Systems Financing, Health Financing Policy. Number 1. 2005

Widodo Teguh. Penerapan Sistem Asuransi Kesehatan Nasional pada Seluruh Penduduk Jepang. Tesis FIB. Universitas Indonesia. Depok. 2014. 